\title{
Cathodic Limiting Current of Zine Ion on the Electrolysis in Fused Fluoride Salt Solutions*
}

\section{Hidehiko Kido**, Osamu Matsumoto** and Yasumasa HAyAKAwA**}

Application of the polarographic method to the study of fused salt systems has been attempted only recently(1). P. Drossbach(2) introduced the relationship between the limiting current density and the diffusion coefficient theoretically,

$$
D=\left(I g / c_{0}\right) r d
$$

where $D$ : Diffusion coefficient

$\gamma$ : Quantity of metal deposited by $1 \mathrm{~A}$ sec. current

$I_{g}$ : Cathodic limiting current density

$d$ : Half of distance between anode and cathode

If the initial concentration of the metallic ion is proportional to the cathodic limiting current density,

$$
c_{0}=k I_{g}
$$

where $k$ is a proportional constant.

Substituting (2) in (1),

$$
D=r d / k
$$

He evaluated the diffusion coefficient of copper, cadmium, cobalt, nickel and silver ions in the fused mixture of potassium chloride and lithium chloride from the determined limiting current using the tungsten cathode and carbon anode. The authors measured the diffusion current of zinc ion in the four kinds of fused solvents having the following composition, and calculated the diffusion coefficient of zinc ion in each solvent (Table 1).

In the preheated electric furnace, the platinum crucible containing the mixture of zinc chloride and fluorides was set, and after heating at the temperature of $30 \sim 40^{\circ} \mathrm{C}$ above the melting point of each mixture of fluorides, the microplatinum cathode $(0.042 \mathrm{~cm}$ dia) and the flat platinum anode (2 $\mathrm{cm}$ square) were immersed $1 \mathrm{~cm}$ apart in the melt of fluoride salts. Then the cathodic limiting current were measured in each concentration of zinc ion in each fluoride bath.

Tables $2 \sim 5$ show the cathodic limiting current density determined in each solvents. Fig. 1 shows, as an example, the proportionality of the cathodic limiting current density against the concentration of zinc in the solvent of sodium fluoride (54 mol \%)-aluminum

Table 1 Fused Solvents of Mixed Fluorides

\begin{tabular}{c|c|c}
\hline System & Ratio (mol \%) & Melting point ${ }^{\circ} \mathrm{C}$ \\
\hline $\mathrm{NaF}-\mathrm{CaF}{ }_{2}$ & $67.5: 32.5$ & 810 \\
$\mathrm{NaF}-\mathrm{AlF}_{3}$ & $87.0: 13.0$ & 885 \\
$\mathrm{NaF}-\mathrm{AlF}_{3}$ & $54.0: 46.0$ & 685 \\
$\mathrm{CaF}_{2}-\mathrm{AlF}_{3}$ & $64.0: 36.0$ & 820 \\
\hline
\end{tabular}

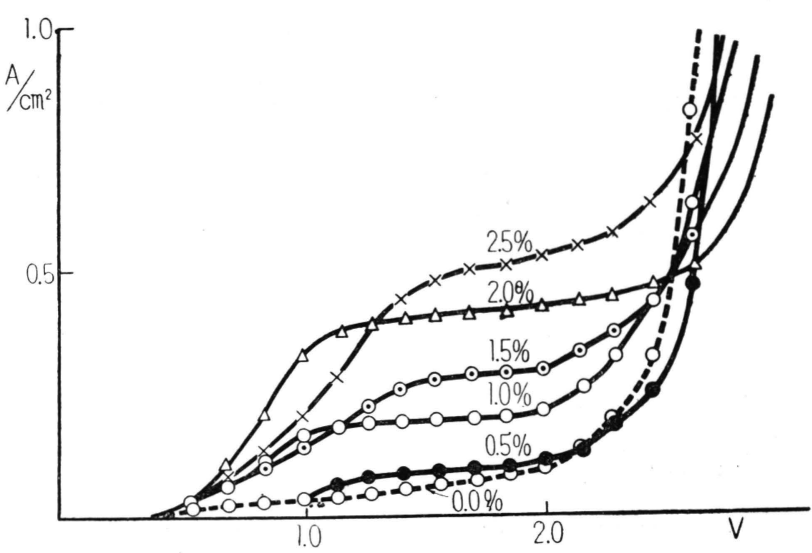

Fig. 1 The cathodic limiting current density on the electrolysis of zinc chloride in the melt of $\mathrm{NaF}(54 \mathrm{~mol} \%)-\mathrm{AlF}_{3}(46 \mathrm{~mol} \%)$ mixture.

* Studies on the Cathodic Limiting Current of Fused Salts (Part 1)

** Dept. of Chemistry, College of Liberal Arts, Saitama University, Urawa

The original written in Japanese can be seen in J. Electrochem. Soc. Japan, 26, 289 (1958) 
fluoride $(46 \mathrm{~mol} \%)$. Tables $6 \sim 9$ show the diffusion coefficient deduced from limiting current density using the relation between diffusion coefficient and limiting current density.

Table 2 Cathodic limiting current density of Zinc ion in the melt of $\mathrm{NaF}$ (54.0 mol \%) $-\mathrm{AlF}_{3}(46 \mathrm{~mol} \%)$ mixture

\begin{tabular}{c|c|c|c|c}
\hline \hline$C_{0} \cdot 10^{2} \mathrm{~mol} \%$ & $I_{g}$ & $I_{g} / \mathrm{cm}^{2}$ & $t$ melt ${ }^{\circ} \mathrm{C}$ & $t$ meas ${ }^{\circ} \mathrm{C}$ \\
\hline 0.5 & 0.0084 & 0.089 & 720 & $780 \pm 2$ \\
1.0 & 0.0182 & 0.194 & 720 & $780 \pm 2$ \\
1.5 & 0.0295 & 0.414 & 720 & $780 \pm 2$ \\
2.0 & 0.0400 & 0.426 & 720 & $780 \pm 2$ \\
2.5 & 0.0500 & 0.514 & 720 & $780 \pm 2$ \\
\hline
\end{tabular}

Table 3 Cathodic limiting current density of Zinc ion in the melt of $\mathrm{NaF}(87.0$ mol \%) $-\mathrm{AlF}_{3}(13.0 \mathrm{~mol} \%)$ mixture

\begin{tabular}{c|c|c|c|c}
\hline \hline$C_{0} \cdot 10^{2} \mathrm{~mol} \%$ & $I_{g}$ & $I_{g} / \mathrm{cm}^{2}$ & $t$ melt $^{\circ} \mathrm{C}$ & $t$ meas ${ }^{\circ} \mathrm{C}$ \\
\hline 0.5 & 0.0093 & 0.098 & 905 & $935 \pm 3$ \\
1.0 & 0.0202 & 0.212 & 905 & $940 \pm 5$ \\
1.5 & 0.0316 & 0.355 & 905 & $940 \pm 5$ \\
2.0 & 0.0444 & 0.471 & 905 & $940 \pm 5$ \\
\hline
\end{tabular}

Table 4 Cathodic limiting current density of Zinc ion in the melt of $\mathrm{NaF}$ (67.5 $\mathrm{mol} \mathrm{\% )}-\mathrm{CaF}_{2}(32.5 \mathrm{~mol} \%)$ mixture

\begin{tabular}{c|c|c|c|c}
\hline \hline$C_{0} \cdot 10^{2} \mathrm{~mol} \%$ & $I_{g}$ & $I_{g} / \mathrm{cm}^{2}$ & $t$ melt ${ }^{\circ} \mathrm{C}$ & $t$ meas $^{\circ} \mathrm{C}$ \\
\hline 0.5 & 0.0105 & 0.112 & 820 & $850 \pm 3$ \\
1.0 & 0.0218 & 0.231 & 820 & $850 \pm 3$ \\
1.5 & 0.0332 & 0.352 & 820 & $850 \pm 3$ \\
2.0 & 0.0540 & 0.572 & 820 & $850 \pm 3$ \\
\hline
\end{tabular}

Table 5 Cathodic limiting current density of Zinc ion in the melt of $\mathrm{AlF}_{3}(36 \mathrm{~mol}$ $\%)-\mathrm{CaF}_{2}(64 \mathrm{~mol} \%)$ mixture

\begin{tabular}{c|c|c|c|c}
\hline \hline$C_{0} \cdot 10^{2} \mathrm{~mol} \%$ & $I_{g}$ & $I_{g} / \mathrm{cm}^{2}$ & $t$ melt $^{\circ} \mathrm{C}$ & $t$ meas $^{\circ} \mathrm{C}$ \\
\hline 0.5 & 0.0092 & 0.098 & 840 & $880 \pm 5$ \\
1.0 & 0.0211 & 0.224 & 840 & $880 \pm 5$ \\
1.5 & 0.0302 & 0.329 & 840 & $880 \pm 5$ \\
\hline
\end{tabular}

Table 6 The diffusion coefficient of Zinc ion in the melt of $\mathrm{NaF}(54.0 \mathrm{~mol} \%)$ $\mathrm{AlF}_{3}(46 \mathrm{~mol} \%)$ mixture

\begin{tabular}{c|c|c|c}
\hline \hline$C_{0} \cdot 10^{2} \mathrm{~mol} \%$ & $I_{g} / \mathrm{cm}^{2}$ & $k\left(C_{0} / I_{g}\right) \cdot 10^{2}$ & $D \cdot 10^{5} \mathrm{~cm} / \mathrm{sec}$ \\
\hline 0.5 & 0.089 & 5.61 & 0.92 \\
1.0 & 0.194 & 5.15 & 1.00 \\
1.5 & 0.314 & 4.79 & 1.08 \\
2.0 & 0.426 & 4.72 & 1.09 \\
2.5 & 0.514 & 4.62 & 1.11 \\
\hline
\end{tabular}

Table 7 The diffusion coefficient of Zinc ion in the melt of $\mathrm{NaF}(87 \%)-\mathrm{AlF}_{3}(13 \%)$ mixture

\begin{tabular}{c|c|c|c}
\hline \hline$C_{0} \cdot 10^{2} \mathrm{~mol} \%$ & $I_{g} / \mathrm{cm}^{2}$ & $k\left(C_{0} / I_{g}\right) \cdot 10^{2}$ & $D \cdot 10^{5} \mathrm{~cm} / \mathrm{sec}$ \\
\hline 0.5 & 0.089 & 5.08 & 0.99 \\
1.0 & 0.212 & 4.71 & 1.09 \\
1.5 & 0.355 & 4.47 & 1.15 \\
2.0 & 0.471 & 4.25 & 1.21 \\
\hline
\end{tabular}

Table 8 The diffusion coefficient of $\mathrm{Zinc}$ ion in the melt of $\mathrm{NaF}(67.5 \mathrm{~mol} \%)-$ $\mathrm{CaF}_{2}(32.5 \mathrm{~mol} \%)$ mixture

\begin{tabular}{c|c|c|c}
\hline \hline$C_{0} \cdot 10^{2} \mathrm{~mol} \%$ & $I_{g} / \mathrm{cm}^{2}$ & $k\left(C_{0} / I_{g}\right) \cdot 10^{2}$ & $D \cdot 10^{5} \mathrm{~cm} / \mathrm{sec}$ \\
\hline 0.5 & 0.112 & 4.47 & 1.15 \\
1.0 & 0.231 & 4.33 & 1.18 \\
1.5 & 0.352 & 4.26 & 1.21 \\
2.0 & 0.572 & 3.49 & 1.48 \\
\hline
\end{tabular}

Table 9 The diffusion coefficient of Zinc ion in the melt of $\mathrm{AlF}_{3}(36 \mathrm{~mol} \%)-\mathrm{CaF}_{2}$ $(64 \mathrm{~mol} \%)$ mixture

\begin{tabular}{c|c|c|c}
\hline \hline$C_{0} \cdot 10^{2} \mathrm{~mol} \%$ & $I_{g} / \mathrm{cm}^{2}$ & $k\left(C_{0} / I_{g}\right) \cdot 10^{2}$ & $D \cdot 10^{5} \mathrm{~cm} / \mathrm{sec}$ \\
\hline 0.5 & 0.093 & 5.40 & 0.95 \\
1.0 & 0.224 & 4.46 & 1.15 \\
1.5 & 0.320 & 4.68 & 1.10 \\
\hline
\end{tabular}

The cathodic current density in the polarographic electrolysis of zinc chloride in various kinds of fluoride baths showed that the current density is approximately proportional to the initial concentration of zinc chloride (Fig. 2).

The diffusion constant of zinc ion calculated from the cathodic limiting current density is constant at the concentration of more than $1 \%$ of zinc chloride as shown in Fig. 3 . In the region of lower concentration, the slight increase with increase of the concentration is to be ascribed to the evolution of anode gas.

The effect of addition of calcium fluoride to the solvent to favor increase the diffusion of zinc ion might be interpreted from the relationship between the diffusion coefficient and the viscosity of fluoride bath. 


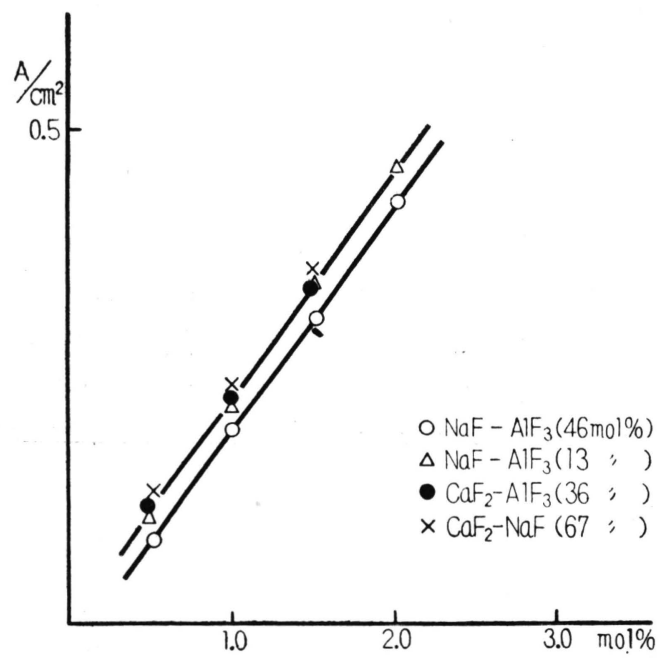

Fig. 2 Relationship between the initial concentration of zinc chloride and cathodic limiting current density.

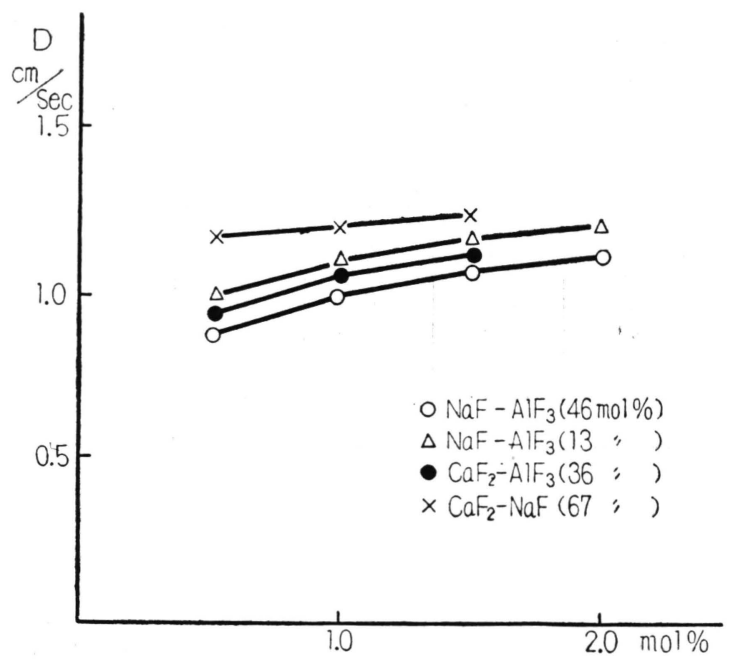

Fig. 3 Relationship between the concentration of zinc chloride and diffusion coefficient.

(Received May 31, 1957)

\section{Literature :}

(1) Yu. S. Lyalikov, V.I. Karmazim : Zavodskaya Lab., 14, 144 (1948)

E.D. Bleck, T. De Vries : Anal. Chem., 27, 906 (1955)

(2) P. Drossbach : Z. Elektrochem., 58, 66,95 (1954) 